\title{
Combined TGA-MS kinetic analysis of multistep processes. Thermal decomposition and ceramification of polysilazane and polysiloxane preceramic polymers.
}

García-Garrido, C. ${ }^{a,}$, Sánchez-Jiménez, P.E. ${ }^{a,{ }^{*}}$, Pérez-Maqueda, L.A. ${ }^{a}$, Perejón, $A^{a, b}$ and José M. Criado ${ }^{a}$.

\footnotetext{
${ }^{a}$ Instituto de Ciencia de Materiales de Sevilla (CSIC - Univ. Sevilla), C. Américo Vespucio 49, 41092 Sevilla, Spain

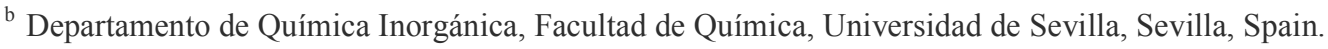

\begin{abstract}
The polymer-to-ceramic transformation kinetics of two widely employed ceramic precursors; 1,3,5,7-tetramethyl-1,3,5,7-tetravinylcyclotetrasiloxane (TTCS) and polyureamethylvinylsilazane (CERASET) have been investigated using coupled thermogravimetry and mass spectrometry (TG-MS), Raman, XRD and FTIR. The thermally induced decomposition of the pre-ceramic polymer is the critical step in the synthesis of Polymer Derived Ceramics (PDCs) and an accurate kinetic modeling is key to attain a complete understanding of the underlying process and to attempt any behavior predictions. However, obtaining a precise kinetic description of processes of such complexity, consisting of several largely overlapping physico-chemical processes comprising the cleavage of the starting polymeric network and the release of organic moieties, is extremely difficult. Here, using the evolved gases detected by MS as a guide it has been possible to determine the number of steps that compose the overall process, which was subsequently resolved using a semiempirical deconvolution method based on the Frasier-Suzuki function. Such function is more appropriate that the more usual Gaussian or Lorentzian functions since it takes into account the intrinsic asymmetry of kinetic curves. Then, the kinetic parameters of each constituent step was independently determined using both model-free and model-fitting procedures, finding the processes obey mostly diffusion models that can be attributed to the diffusion of the released gases through the solid matrix. The validity of the obtained kinetic parameters was tested not only by the successful reconstruction of the original experimental curves but also by predicting the kinetic curves of the overall processes yielded by different thermal schedules and by a mixed TTCS-CERASET precursor.
\end{abstract}

KEYWORDS: Kinetics, Deconvolution, Frasier-Suzuki, Polymer-Derived Ceramics, Thermal decomposition;

*Corresponding authors:

Cristina García-Garrido:cristina.garrido@icmse.csic.es

Pedro E. Sánchez-Jiménez: pedro.enrique@icmse.csic.es 


\section{TABLE OF CONTENTS}
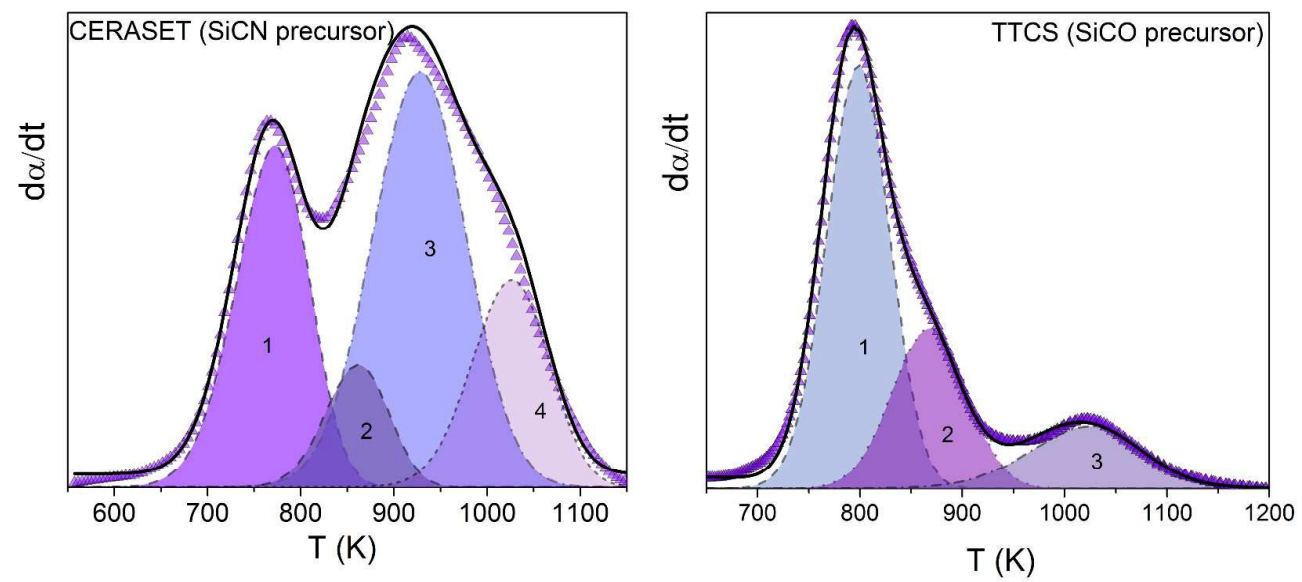

Kinetic study of the complex ceramification of preceramic polymeric precursors using a deconvolution process supported by coupled TGA + MS 


\section{Introduction}

Ceramic materials prepared from polymer precursors, also known as polymer-derived ceramics (PDCs), are a subject of the most interest that has received extensive atention in the last years ${ }^{1-}$ 7. These materials are prepared from a preceramic polymer that is first cured and then ceramified by controlled pyrolysis at relatively low temperatures as compared with those needed in conventional ceramic processing from ceramic powders ${ }^{8-13}$. Thus, since the polymeric precursor can be handled using simple polymer processing techniques, structures such as films, fibers, mesoporous monoliths or even complex shapes can be directly obtained in a near-net shape process ${ }^{2,6,14-18}$. PDCs are generally amorphous non oxide ceramics, mainly based on Si, C, H, N and O but may contain other elements such as $\mathrm{Li}, \mathrm{B}$ or $\mathrm{Al}{ }^{16,19-22}$. The chemical composition and properties of the ceramic strongly depend on both the precursor chemistry and the conditions under which the polymer-to-ceramic transformation is carried out. Thus, it is possible to tailor as desired both properties and structure by carefully controlling the processing conditions ${ }^{23-28}$. PDCs display several interesting properties; a high thermal and chemical resistance, a remarkable resistance to creep, high piezoresistivity, semiconductivity at high temperature and oxidation resistance, ${ }^{29-32}$ that make them useful for a range of potential applications such as high temperature sensors ${ }^{33-37}$, anodes in lithium-ion batteries ${ }^{27,38-45}$, protective coatings or catalyst support at high temperatures ${ }^{46}$.

The critical step in the synthesis of PDCs is the thermally induced decomposition of the preceramic polymer, consisting of the release of organic moieties followed by a structural rearrangement that eventually leads to the formation of the final ceramic material $3-5,8,47$. Despite the importance of this polymer-to-ceramic transformation, save for a few exceptions, 48-52 detailed kinetic studies of these processes are mostly absent due to the complexity of the chemical pathways involved, consisting of several overlapping reactions. So far, authors have studied these complex processes using peak-fitting methodologies in which the overall process is separated into its constituent steps using a set of Gaussian or Lorentzian functions to fit the derivative thermogravimetric curve (DTG) ${ }^{48,50,53}$. However, it has been recently shown that such commonly used symmetrical fitting functions are inadequate for kinetic analysis purposes due to the fact that the kinetic curves (represented as conversion rate versus temperature or time) in solid state reactions are asymmetrical. Since the shape of the differential curve is related to the kinetic mechanism ${ }^{54}$, the fit of the experimental data to symmetrical functions necessarily forces a kinetic function onto the data, thereby biasing the analysis and producing incorrect results ${ }^{55}$. Thus, the Frasier-Suzuki algorithm was proposed as an alternative ${ }^{55}$. Since 
the publication of the original Perejon et al. paper, several authors have employed FrasierSuzuki functions to study complex processes as varied as the decomposition of co-precipitated zinc carbonates $^{56}$, polymer $^{57}$ and polymer-clay composites $^{58}$, energetic materials ${ }^{59}$ chalcogenide crystallizations ${ }^{60,}{ }^{61}$, overlapped phase transitions in $\mathrm{BiFeO}_{3}{ }^{62}$, biomass pyrolysis $^{63,64}$ and the multistep decomposition of silver carbonates ${ }^{56,65,66}$. In this paper, this methodology is used to study the kinetics of two pre-ceramic polymer decomposition processes. Two widely employed polymeric precursors; polyureamethylvinylsilazane (SiCN precursor) and 1,3,5,7-Tetramethyl-1,3,5,7- tetravinylcyclotetrasiloxane (SiCO precursor) have been studied by means of coupled mass spectrometry and thermogravimetry (MS-TGA). The different mass spectrometry profiles recorded during the polymer degradation are used to determine the number of contributing steps to be separated by the deconvolution procedure. Once separated, the individual processes are studied independently, using both isoconversional and combined kinetic analysis methods. The validity of the resulting kinetic parameters and its prediction capability is tested by the reconstruction of the original experimental curves and by predicting experimental curves not used in the analysis. The results herein presented provide a better comprehension of the transformation process from polymer to ceramic and, at the same time, the necessary tools to model the ceramification so that processing conditions can be optimized in order to obtain a higher quality ceramic. Moreover, the procedure herein shown could be easily extended to any other preceramic polymers, regardless of composition.

\section{Theoretical}

The reaction rate, $\mathrm{d} \alpha / \mathrm{dt}$, of a solid state reaction can be described by the following general equation:

$$
\frac{d \alpha}{d t}=A \exp (-E / R T) f(\alpha)
$$

where $A$ is the Arrhenius pre-exponential factor, $R$ is the ideal gas constant, $E$ the activation energy, $\alpha$ the reacted fraction, $T$ is the process temperature and $f(\alpha)$ accounts for the reaction rate dependence on $\alpha$. The kinetic model $f(\alpha)$ is an algebraic expression which is usually associated with a physical model that describes the kinetics of the solid state reaction. Table 1 lists some of the most commonly used kinetic models found in literature. In this work, the 
reacted fraction, $\alpha$, has been expressed with respect to the overall mass loss of each polymeric precursor, as defined below:

$$
\alpha=\frac{w_{0}-w}{w_{0}-w_{f}}
$$

where $w_{o}$ is the initial mass of precursor, $w_{f}$ the mass of the ceramic yield and $w$ the sample mass at an instant $t$. 
TABLE 1. $f(\alpha)$ kinetic functions for the most widely used kinetic models.

\begin{tabular}{lll}
\hline Mechanism & Symbol & $\mathbf{f}(\alpha)$ \\
\hline $\begin{array}{l}\text { Phase boundary controlled reaction } \\
\text { (contracting area) }\end{array}$ & R2 & $(1-\alpha)^{1 / 2}$
\end{tabular}

Phase boundary controlled reaction

(contracting volume)

R3 $(1-\alpha)^{2 / 3}$

Random nucleation followed by an instantaneous growth of nuclei.

F1 $\quad(1-\alpha)$

(Avrami-Erofeev eqn. $n=1$ )

Random nucleation and growth of nuclei through different nucleation An $n(1-\alpha)[-\ln (1-\alpha)]^{1-1 / n}$ and nucleus growth models. (Avrami-

Erofeev eq. $\mathrm{n} \neq 1$.)

Two-dimensional diffusion

Three-dimensional diffusion

(Jander equation)

Three-dimensional diffusion

(Ginstling-Brounshtein equation)

D4

L2

$1 /[-\ln (1-\alpha)]$

Random Scission L=2

Random Scission L $>2$
D2

$$
\frac{3(1-\alpha)^{2 / 3}}{2\left[1-(1-\alpha)^{1 / 3}\right]}
$$

D3

$$
\frac{3}{2\left[(1-\alpha)^{-1 / 3}-1\right]}
$$

Ln

$+2$

No symbolic solution 


\subsection{Isoconversional model-free Analysis}

Isoconversional or "model-free" methods are commonly employed for determining the apparent activation energy as a function of the reacted fraction so that a previous knowledge of the kinetic model driving the process is not required ${ }^{67-70}$. The Friedman isoconversional method is a widely used differential method that provides accurate values of the activation energies even if they were a function of the reacted fraction. Eq. (1) can be written in logarithmic form:

$$
\ln \left(\frac{d \alpha}{d t}\right)=\ln (A f(\alpha))-\frac{E}{R T}
$$

The activation energy at a constant $\alpha$ value can be determined from the slope of the plot of the left hand side of Eq. (3) against the inverse of the temperature, at constant values of $\alpha$.

\subsection{Combined Kinetic Analysis.}

The logarithmic form of the general kinetic Eq. (1) can be rewritten as follows:

$$
\ln \left(\frac{d \alpha / d t}{f(\alpha)}\right)=\ln A-\frac{E}{R T}
$$

The plot of the left hand side of the equation versus the inverse of the temperature will yield a straight line if the proper $f(\alpha)$ is considered for the analysis ${ }^{71}$. The intercept of the plot leads to the pre-exponential factor whereas the activation energy is obtained from the slope. As no assumption regarding the thermal pathway is made in Eq. (4), the kinetic parameters obtained should be independent of the thermal pathway. Therefore, any set of experimental curves recorded under different thermal schedules can be analyzed simultaneously ${ }^{72}$. In order to determine the kinetic model, $f(\alpha)$, the reaction obeys, an optimization procedure is employed. A modified Sestak and Bergen equation is used as a fitting function since it has been previously shown that, by merely adjusting the parameters $\mathrm{c}, \mathrm{n}$ and $\mathrm{m}$, such equation fits every kinetic ideal model proposed for solid state reactions, and also accounts for the deviations of the ideal kinetic models due to, for example, inhomogeneities in particle size and shapes ${ }^{72}$. Introducing the modified Sestak-Berggren equation in Eq. (4) we get:

$$
\ln \left(\frac{d \alpha / d t}{(1-\alpha)^{n} \alpha^{m}}\right)=\ln c A-E / R T
$$


The Pearson linear correlation coefficient between the left hand side of the equation and the inverse of the temperature is set as an objective function for optimization. By means of the maximize function of the software Mathcad, the values of $E, A, n$ and $m$ leading to the best linear correlation for the whole set of $\alpha-T$ plots is obtained ${ }^{72}$. Nevertheless, it should be noted that the combined analysis approach rests in the assumption that the reaction can be described by a single set of kinetic parameters and, consequently, single activation energy. Therefore, a complex process must first be separated into its constituent steps before the method can be correctly applied.

\section{Experimental}

In this paper, two commercial polymeric precursors have been studied: polyureamethylvinylsilazane (CERASET, Polysilazane) (Clariant Corp., PA, USA) and 1, 3, 5, 7-Tetramethyl- 1, 3, 5, 7- tetravinylcyclotetrasiloxane (TTCS) (Geleset, USA). Ceraset is precursor to a $\mathrm{SiCN}$ type ceramic while TTCS produces a SiCO ceramic. The liquid polymeric precursors were mixed with $1 \mathrm{wt} \%$ curing agent, Bis (1-methyl-1-phenylethyl)peroxide 98\% (dicumyl peroxide) (Sigma Aldrich, product number 329541) in a glovebox to prevent the oxidation of the polymers and magnetically stirred at room temperature. The liquid polymeric precursors were then thermally cross-linked at $653 \mathrm{~K}$ for $5 \mathrm{~h}$ in inert argon atmosphere, using heating and cooling rates of $1.5 \mathrm{~K} / \mathrm{min}$. The resulting hard resin was grounded into a powder by ball milling at $350 \mathrm{rpm}$ using zirconia balls (Fritsch Pulverissette Analyssette laborette, IdarOberstein, Germany).

Coupled thermogravimetric and mass spectrometry (TGA-MS) measurements were carried out with a homemade instrument that uses a CI Electronics Ltd electrobalance (Salisbury, United Kingdom) connected to a commercial mass spectrometer (PFEIFFER Vacuum Prisma (Asslar, Germany) with a working pressure of $5 \times 10^{-5}$ mbar and a gas flow system to work in inert atmosphere $(135 \mathrm{ml} / \mathrm{min} \mathrm{Ar})$. Special attention was paid into assuring the inertness of the atmosphere since the preceramic polymers are very sensitive to oxygen during ceramification and any oxidation process undergone by the sample would interfere with the polymer decomposition. Thus, by previously applying several vacuum/fill cycles it was possible to reduce the oxidation of the ceramic to negligible levels during the experiment. Moreover, no oxygen was detected with the MS during the experiment. Sample powders were placed on a 1$\mathrm{cm}$ diameter alumina pan inside a homemade low thermal inertia furnace. Sample sizes of 
about $40 \mathrm{mg}$ were used to ensure intense signals were detected in the MS. An inconel capillar, placed just above the sample crucible transported the evolved gases to the MS driven by the vacuum created with a secondary pump. An installed special gas dosing valve (type EVN116, PFEIFFER Vacuum Prisma (Asslar, Germany)) in the system allows an exhaustive control of the introduced gas flow in the mass spectrometer and, therefore, a precise and constant control of the pressure into mass spectrometer chamber, $5.10^{-5} \mathrm{mbar}$, as aforementioned.

A set of thermal degradation experiments, obtained under both linear heating rate and isothermal conditions were carried out for each already cross-linked polymeric precursor. The $\alpha-\mathrm{T}$ (or time) plots obtained from these methods were differentiated by means of the Origin software (OriginLab) to get the differential curves employed in the kinetic analysis. The deconvolution of the differential curves was performed by nonlinear least squares curve fitting by means of the Peakfit software (Systat Software Inc.) using Frasier-Suzuki as a fitting function after adding it to the software as user defined function. The optimization procedure needed for the combined kinetic analysis and the curve reconstruction was developed out using Mathcad software (Mathsoft, Cambridge, MA, USA).

The powders obtained after the thermal degradation experiments were characterized by X-Ray Diffraction (XRD), Raman Spectroscopy, FTIR Spectroscopy and Scanning Electron Microscopy. XRD spectra were collected with a Panalytical X'Pert Pro diffractometer working at $45 \mathrm{kV}$ and $40 \mathrm{~mA}$, using $\mathrm{CuK} \alpha$ radiation and equipped with an $\mathrm{X}^{\prime}$ Celerator detector and a graphite diffracted beam monochromator. Raman spectra were collected with a HORIBA HR $800 \mathrm{UV}$ spectrometer, using an excitation wavelength of $514.5 \mathrm{~nm}$ (green laser). The FTIR spectra were recorded in the middle infrared range $\left(500-4000 \mathrm{~cm}^{-1}\right)$ using a JASCO FT/IR6200 spectrometer. Sample was prepared for measurement by means of the standard $\mathrm{KBr}$ pellet technique. SEM images were obtained using a HITACHI S-4800 Scanning Electron Microscope. 


\section{Results and Discussion}

Description of the thermal degradation of 1, 3, 5, 7-tetramethyl-1, 3, 5, 7tetravinylcyclotetrasiloxane (TTCS) and polyureamethylvinilsilazane (CERASET)

Figure 1 shows the experimental thermogravimetric mass-T curve recorded for the thermal degradation of both TTCS and CERASET precursor under linear heating rate conditions $\left(5 \mathrm{~K} \mathrm{~min}^{-1}\right)$.

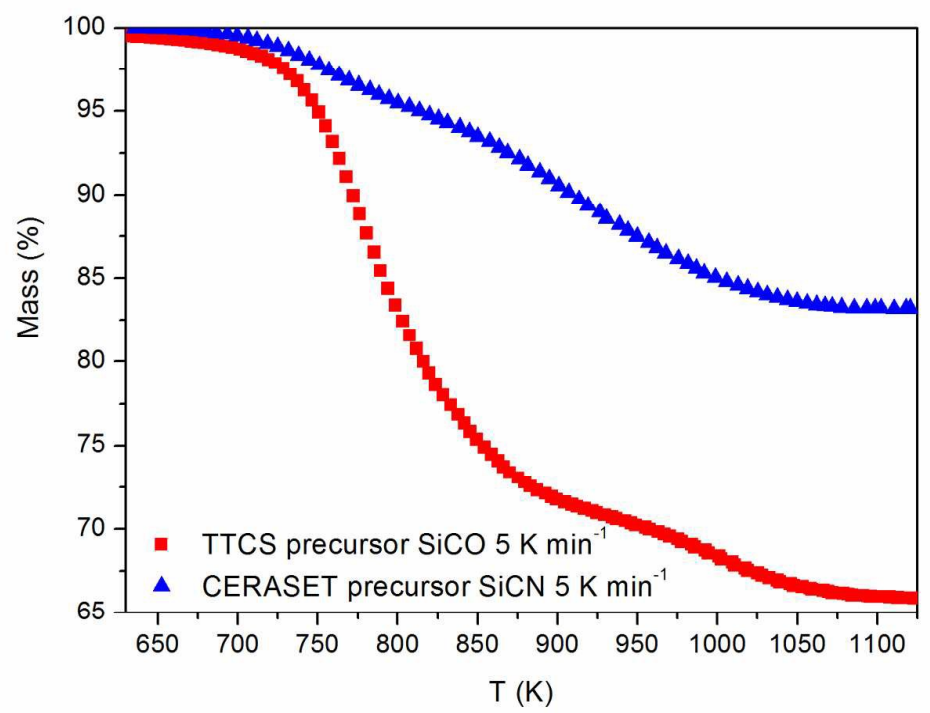

Figure 1. Experimental mass \%-T curves recorded for the thermal decomposition of CERASET and TTCS in Ar gas flow and using a linear heating rate of $5 \mathrm{~K} \mathrm{~min}^{-1}$.

It is noticeable the much higher ceramic yield of the Ceraset derived $\mathrm{SiCN}$ ceramic. This is due to the chemical architecture of the precursor which is usually tailored according to the properties desired for the final ceramic. In an oversimplified manner, organosilicon polymers can be described by the general formula, $-\left[\mathrm{R}^{1} \mathrm{R}^{2} \mathrm{SiX}\right]_{\mathrm{n}}-$. By changing the functional groups $\mathrm{R}^{1}$ and $\mathrm{R}^{2}$ the properties of the polymer can be adjusted as well as the free carbon content and ceramic yield of the ceramic derived therefrom ${ }^{8}$. High molecular weight polymers and the introduction of organic groups favouring crosslinking reactions generally produce higher ceramic yields. The allyl groups and the 
$\mathrm{Si}-\mathrm{H}$ bonds in Ceraset promote the formation of a heavily crosslinked structure that leads to a higher yield ${ }^{8}$.

In order to study the changes produced on the material during the ceramification process, the reaction was interrupted at three different temperatures; $823 \mathrm{~K}, 1023 \mathrm{~K}$ and $1273 \mathrm{~K}$. The resulting powders were collected and studied by X-Ray Difraction, Raman Spectroscopy, FTIR Spectroscopy and Scanning Electron Microscopy. The colour of pyrolyzed powders obtained at different temperature changed from white (initial precursor) to black (fully ceramified at $1273 \mathrm{~K}$ ) going over different brownish colours at intermediate temperatures $(823 \mathrm{~K}$ and $1023 \mathrm{~K})$. Moreover, the XRD diffractograms of the powders show that the material remains amorphous, as expected for polymer derived silicon oxycarbides and silicon carbonitrides ceramics after pyrolysis at these temperatures (See supplementary Information, Figures S2.a and S2.b) ${ }^{3,73}$.

Figure 2 includes the Raman spectra, which provide information about the structural organization of the free carbon phase in PDCs ${ }^{74-78}$, measured at different temperatures. Raman spectra of the TTCS derived powders (Figure 2a) exhibit no significant features due to a completely amorphous carbon phase up to a temperature of about $1273 \mathrm{~K}$, at which point the free carbon nanocrystalline clusters develop ${ }^{74-79}$. On the other hand, the pyrolysed CERASET precursor shows no Raman bands even at $1273 \mathrm{~K}$ (Figure 2b). This might indicate that the development of the carbon nanocrystalline structure is kinetically controlled so that annealing for a minimum time at a temperature of 900$1000{ }^{\circ} \mathrm{C}$ is required, at least in the case of low carbon content ceramics as Ceraset derived SiCN. 

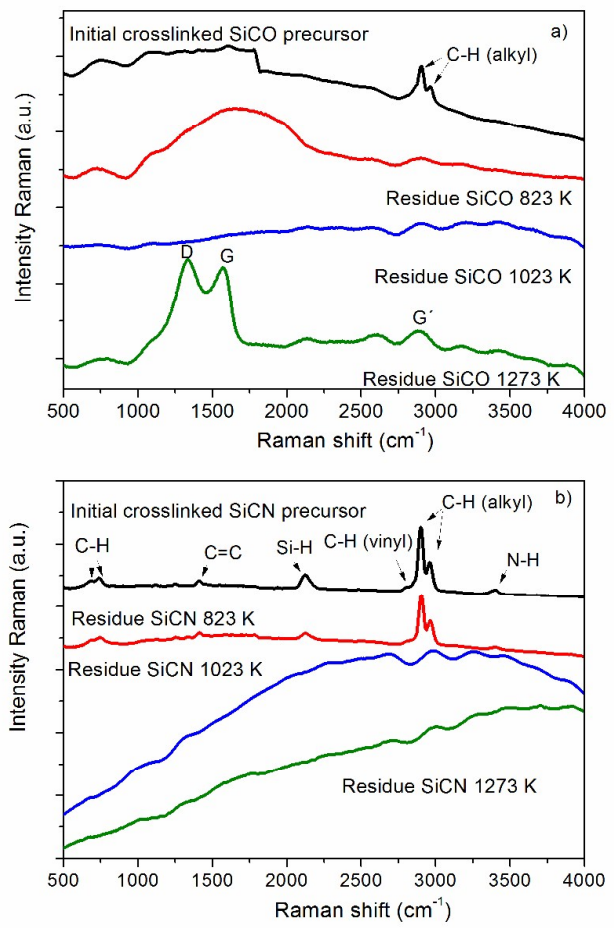

Figure 2. Raman spectra of the powders collected after interrupting the pyrolysis of (a) TTCS precursor and (b) CERASET precursor at $823 \mathrm{~K}, 1023 \mathrm{~K}, 1273 \mathrm{~K}$.

Figure 3 shows the FTIR spectra of the cross-linked preceramic polymers and the subsequent powders obtained at $823 \mathrm{~K}, 1023 \mathrm{~K}$ and $1273 \mathrm{~K}$. It can be inferred of the FTIR the transformation of the initial polymeric network into the final silicon based ceramic as the bands corresponding to the different organic groups gradually disappear until only the broad band corresponding to $\mathrm{Si}-\mathrm{C}$ and $\mathrm{Si}-\mathrm{O}$ vibrations remains ${ }^{80}$ A more detailed analysis can be found in the Supplementary Information section.

SEM micrographs are shown in the Supplementary Information (Figure S3) illustrating the lack of significant microstructural differences between the initial cross-linked precursor and the as pyrolysed residue obtained at $1273 \mathrm{~K}$ in both TTCS and CERASET precursors. All powders are inhomogeneous in both shape and particle size, maintaining the wide particle size distribution typical of ball-milled powders. 

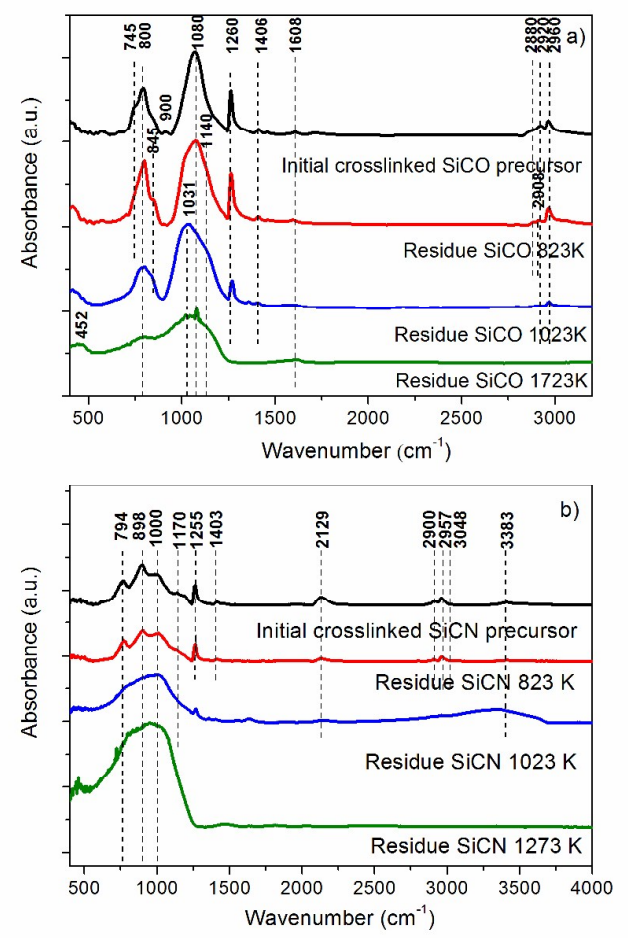

Figure 3. FTIR spectra of the powders collected after interrupting the pyrolysis of (a) TTCS precursor and (b) CERASET precursor at $823 \mathrm{~K}, 1023 \mathrm{~K}, 1273 \mathrm{~K}$. 
Kinetic study of the thermal degradation of 1, 3, 5, 7-Tetramethyl-1, 3, 5, 7tetravinylcyclotetrasiloxane (TTCS)

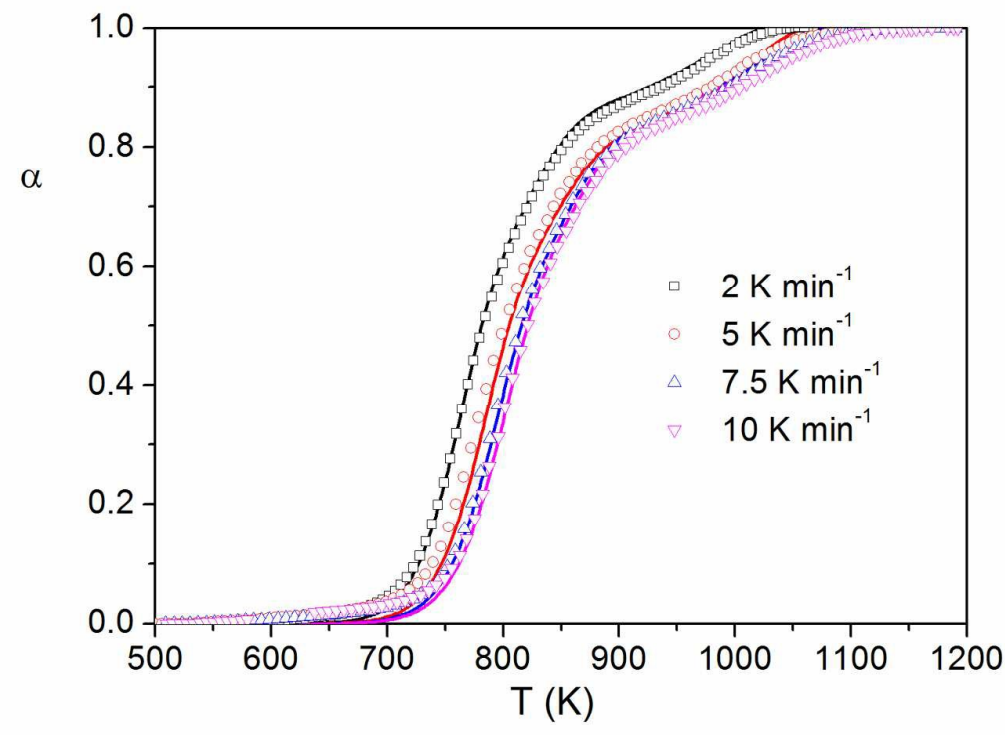

Figure 4. Experimental $\alpha$-T curves (symbols) recorded for the thermal decomposition of TTCS in Ar flow using linear heating rates of 2, 5, 7.5 and $10 \mathrm{~K} \mathrm{~min}^{-1}$. Simulated curves (solid lines) were constructed using the kinetic parameters calculated for TTCS thermal decomposition by the combined analysis method and listed in Table 3.

Figure 4 shows a set of $\alpha$-T curves constructed as per Eq (2) from the experimental data recorded for the TTCS precursor decomposition under linear heating rate conditions $(2$, $5,7.5$ and $10 \mathrm{~K} \mathrm{~min}^{-1}$ ). It is clear from the curve profiles that there are at least two processes involving mass loss occurring during the precursor degradation. The shape of the curves and the overall mass loss remain similar regardless the heating rate. Figure 5 shows the $d \alpha / d t-T$ curve corresponding to the thermal degradation of the TTCS precursor at $5 \mathrm{~K} \mathrm{~min}^{-1}$. The irregular profile indicates this is a complex reaction composed of several individual processes. A main peak at $800 \mathrm{~K}$, a shoulder at about $875 \mathrm{~K}$ and a weak peak at $1050 \mathrm{~K}$ are all clearly noticeable. Most kinetic analysis procedures assume single step processes, described by a single kinetic triplet and, therefore, they cannot be reliably applied to these complex multistep reactions. For that reason, the overall reaction must be separated into its constituent processes, which are then studied separately. When a number of different processes overlap as it happens 
here, a complementary technique is needed to determine and discriminate the number of contributing processes. In this work we have resorted to the volatiles released during the precursor decomposition, which were captured and analysed by the sniffer system and carried to the mass spectrometer. A number of $\mathrm{m} / \mathrm{z}$ values, ranging from $\mathrm{m} / \mathrm{z}=1$ to $\mathrm{m} / \mathrm{z}=$ 45 were recorded in real time during the decomposition with a nearly negligible lag, as shown by the close match of the rate of mass loss curve and the MS intensity profiles. The intensity of the monitored $\mathrm{m} / \mathrm{z}$ signals increases just after the polymer starts losing mass, readily returning to their baseline levels as soon as the process is over. Every single kinetic process that involves a mass loss must produce a single peak in the $\mathrm{d} \alpha / \mathrm{dt}-$ T profile. Accordingly, the released volatiles associated to such mass loss should appear as a peak at the same temperature in the MS intensity-temperature profiles. Thus, by identifying the number of peaks or events contributing to the overall profile it is possible to figure out the number of processes involved. Figure 5 includes the intensity vs. temperature profiles of a few selected $\mathrm{m} / \mathrm{z}$ values recorded with the mass spectrometer during the thermal decomposition of the TTCS precursor. Whereas a higher number of $m / z$ values were monitored, only a few of them are shown in the figure for the sake of clarity. Nevertheless, the entire set can be found in the supplementary information (Fig S4 and S5).

As initially suggested by the d $\alpha / \mathrm{dt}-\mathrm{T}$ profile, three processes can be clearly deduced from the MS spectra. The first process is centered at $800 \mathrm{~K}$, appearing as a single peak in $\mathrm{m} / \mathrm{z}: 16$ and $\mathrm{m} / \mathrm{z}: 30$ profiles and as a shoulder in $\mathrm{m} / \mathrm{z}: 26,27$ and 28 . This process can be attributed to water, methane, ethane, alcoholic and ethylene groups released during the condensation reaction of $\mathrm{Si}-\mathrm{OH}$ and $\mathrm{Si}-\mathrm{OC}_{2} \mathrm{H}_{5}$ groups as well as other condensation reactions of both $\mathrm{Si}-\mathrm{OH}$ and $\mathrm{Si}-\mathrm{OC}_{2} \mathrm{H}_{5}$ groups with $\mathrm{Si}-\mathrm{H}$ group ${ }^{73,81-85}$. The second process, which heavily overlaps the previous one, is shown as a peak at about $875 \mathrm{~K}$ $(\mathrm{m} / \mathrm{z}: 26,27$ and 28) and it might correspond to the release of hydrogen, ethane and ethanoic groups, besides volatile silicon-containing species such as $\mathrm{SiH}_{4}(m / z: 30,31)$ and $\mathrm{CH}_{3} \mathrm{SiH}_{3}(\mathrm{~m} / \mathrm{z}: 45,44)$ which are released due to redistribution reactions involving the exchange of Si-O bonds with $\mathrm{Si}-\mathrm{H}$ bonds and/or Si-C bonds ${ }^{81}$. Finally, the third process, centered at $1025 \mathrm{~K}$, is observed mainly in the $\mathrm{m} / \mathrm{z}$ signal corresponding to hydrogen and methane ${ }^{81} 73,82-85$. This process can be attributed to different cleavage reactions of $\mathrm{Si}-\mathrm{CH}_{3}$ and $\mathrm{Si}-\mathrm{H}$ bonds by $\mathrm{Si}-\mathrm{OH}$, and the homolytic cleavage reactions of $\mathrm{Si}-\mathrm{H}$ and Si-C bonds, leading to the release of $\mathrm{CH}_{4}$ and $\mathrm{H}_{2}$ and the formation of Si-C 
and Si-O bonds as well as the free carbon clusters which are all present in the final silicon oxycarbide ceramic ${ }^{6,86-89}$.

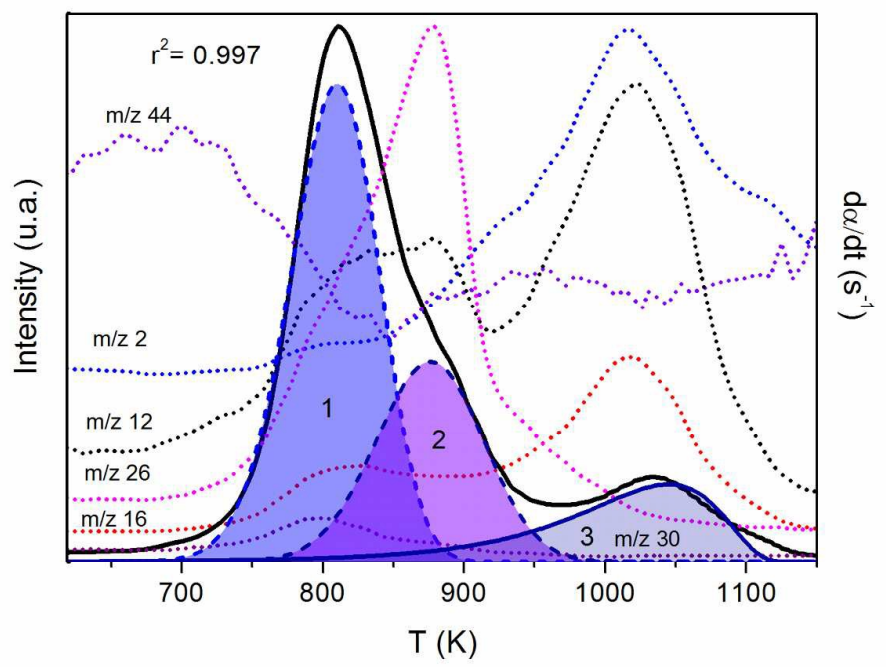

Figure 5. Experimental d $\alpha / \mathrm{dt}-\mathrm{T}$ (solid line) and intensity-T profiles (dotted lines) for several $\mathrm{m} / \mathrm{z}$ ratios obtained for the thermal decomposition of TTCS recorded at $5 \mathrm{~K} / \mathrm{min}$, along with the Fraser-Suzuki function (dotted lines with coloured areas) used for fitting the simulated curves. The correlation coefficient of the fitting has been included into the figure.

It is worthy to clarify at this point that these solid-state processes are quite complex and involve several individual reactions, probably more than the three here proposed. However, TGA is a technique sensitive exclusively to mass changes, so only events directly leading to a release of volatiles are detected. Any subsequent reaction between evolved gases or any bond reorganization process within the nascent ceramic cannot be considered in the kinetic modeling. Nevertheless, the MS profiles and the relative ratios of the different peaks detected prove invariant with the heating rate, what indicates the three proposed steps actually behave as individual, independent, steps. Had any of those steps comprise different processes each described by different kinetic triplets, the profiles would be very sensitive to changes in the heating rate. Thus, such invariance is 
a solid ground on which to assume the three proposed steps correspond to rate limiting steps and can therefore be studied as single processes.

After identifying the three main contributing processes, the overall $\mathrm{d} \alpha-\mathrm{dt}-\mathrm{T}$ curves were deconvolved using Frasier-Suzuki as a fitting function. During the deconvolution procedure, as an additional constraint, the maximum reaction rate of each process was fixed at the temperature at which the MS intensity profiles exhibit a maximum. As an example, Figure 5 shows the results of the deconvolution procedure applied to the degradation curve recorded at $5 \mathrm{~K} \mathrm{~min}^{-1}$ (dotted lines curves with coloured regions). As it can be observed, the overall curve is closely matched by the sum of the individual processes, with a correlation coefficient over 0.997 . The same procedure was applied to the curves recorded at different heating rates, obtaining fairly similar results (See Supplementary Information, Figure S6.a, Figure S6.b and Figure S6.c) A full list including all the fitting parameters yielded by the deconvolution of every individual experimental curve has been included in the Supplementary Information (Table S1). The relative contribution of the first, second and third process to the overall curve is $57 \pm 3 \%, 28 \pm 3 \%$ and $15 \pm 1 \%$, respectively. Remarkably similar contributions are obtained regardless of the heating rate, thereby supporting the idea that each constituent process represents a rate limiting step that occur independently, without need for any of them to finish before the next one can proceed.

Next, the differential curves obtained by deconvolution were integrated and subsequently normalized in order to construct $\alpha$-time and $\alpha$-T curves with $\alpha$ ranging from 0 to 1 . As a result, a set of four $\alpha$-T curves were obtained for each contributing process, and was subsequently analyzed using both isoconversional and combined kinetic methods. Figure 6 shows the apparent activation energy of each process, as determined by Friedman isoconversional method. The values remain reasonably constant along the conversion range, as it should happen in the case of single step processes. There are nevertheless slight deviations that can be attributed to unavoidable errors in the deconvolution of the overall curve that results in slight shape differences in the resolved constituent curves, as well as to experimental errors which are more significant at the very high and low ends of the alpha range. Average apparent activation energy of $200 \mathrm{~kJ} \mathrm{~mol}^{-1}$ was estimated for the first stage, $220 \mathrm{~kJ} \mathrm{~mol}^{-1}$ for the second and $228 \mathrm{~kJ} \mathrm{~mol}^{-1}$ for the third stage. These values are within the range of those obtained for the overall process (Table 2), calculated applying the Friedman 
isoconversional analysis to the overall curve, without deconvolution. Apparent activation energy values in Table 2 exhibit a relatively broad variation with the reaction fraction, as expected for a complex process. Thus, at each reaction fraction, more than one reaction is simultaneously contributing to the overall process and, therefore, the resulting values of activation energy correspond to an average of the different overlapping processes.

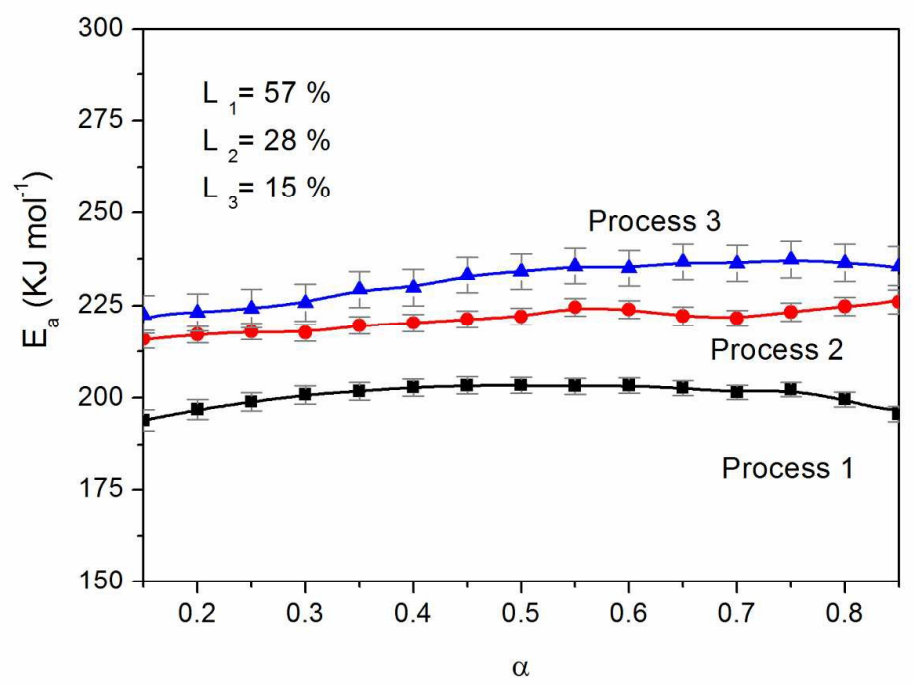

Figure 6. Apparent activation energies at different conversion fraction values for each of the three processes contributing to the thermal decomposition of TTCS, as determined by the Friedman isoconversional method. 
Table 2. Apparent activation energy values at different conversion fractions together with their corresponding correlation coefficients, as obtained by the Friedman isoconversional analysis of the curves showed in Figure 4 (TTCS) and Figure 8 (CERASET).

\begin{tabular}{lllll}
\hline & \multicolumn{2}{c}{ TTCS } & \multicolumn{2}{c}{ CERASET } \\
\hline \hline $\boldsymbol{\alpha}$ & $\boldsymbol{r}$ & $\boldsymbol{E a}\left(\mathrm{kJ} \mathrm{mol}^{-1}\right)$ & $\boldsymbol{r}$ & $\boldsymbol{E a}\left(\mathrm{kJ} \mathbf{m o l}^{-1}\right)$ \\
\hline 0.1 & 0.987 & $215 \pm 3$ & 0.984 & $144 \pm 3$ \\
0.2 & 0.986 & $225 \pm 3$ & 0.986 & $151 \pm 3$ \\
0.3 & 0.986 & $226 \pm 3$ & 0.985 & $155 \pm 3$ \\
0.4 & 0.988 & $227 \pm 3$ & 0.991 & $201 \pm 3$ \\
0.5 & 0.992 & $227 \pm 2$ & 0.997 & $224 \pm 2$ \\
0.6 & 0.995 & $220 \pm 2$ & 0.998 & $229 \pm 2$ \\
0.7 & 0.995 & $206 \pm 2$ & 0.997 & $218 \pm 2$ \\
0.8 & 0.986 & $212 \pm 2$ & 0.999 & $219 \pm 1$ \\
0.9 & 0.998 & $218 \pm 1$ & 0.999 & $202 \pm 1$ \\
\hline
\end{tabular}

Table 3. Average activation energies, preexponential factors, correlation coefficients, $n$ and $m$ values for the three processes contributing to the thermal decomposition of TTCS, as obtained by the combined kinetic analysis applied after deconvoluting the $\mathrm{d} \alpha / \mathrm{dt}$ curves obtained from the curves in Figure 6.

\begin{tabular}{llll}
\hline & PROCESS 1 & PROCESS 2 & PROCESS 3 \\
\hline Ea (KJ/mol) & $200 \pm 1$ & $221 \pm 1$ & $232 \pm 1$ \\
$\boldsymbol{A}\left(\mathbf{s}^{-1}\right)$ & $(7.13 \pm 1.18) \times 10^{10}$ & $(10.92 \pm 1.65) \times 10^{10}$ & $(8.19 \pm 1.59) \times 10^{8}$ \\
$\boldsymbol{r}$ & 0.997 & 0.997 & 0.996 \\
$\boldsymbol{n}$ & 1.338 & 1.438 & 0.596 \\
$\boldsymbol{m}$ & -0.0043 & -0.116 & -1.126 \\
Contribution L (\%) & $57 \pm 3$ & $28 \pm 3$ & $15 \pm 1$ \\
\hline
\end{tabular}


Figure 7a shows the combined kinetic analysis plots (left hand side of Eq. (5) versus 1/T (as detailed in section 2.2) obtained for each contributing process. All data points fit nicely to a straight line, of which the activation energy and preexponential factors can be deduced from the slope and the intercept, respectively. The resulting parameters, along with the correlation coefficients, the contribution of each step to the overall process and both $n$ and $m$ coefficients are all included in Table 3.

In Figure $7 b$, the $f(\alpha)$ conversion functions calculated by the combined kinetic analysis for each individual process are compared with some of the most usual theoretical kinetic models. It is found that, whereas the shape of the resulting conversion functions cannot be fit by any of the ideal models, they all feature a decay trend typical of a diffusion mechanism. Deviations of the ideal models has been found for a large number of systems and could be understood considering that ideal models were proposed assuming a totally homogeneous sample in terms of particle size and shape. However, as it can be seen in the SEM images in Figure S3a. and S3b., the preceramic polymer particles are clearly heterogeneous in both size and shape. Diffusion mechanisms are very appropriate for describing the thermal degradation of a polymer resin which decomposes maintaining the shape but leaving a porous structure. The gases generated during the decomposition close to the particle surfaces are quickly released but those generated in the interior need to diffuse out, thus producing a decaying mass loss rate vs. time trend. For PDCs it has been reported that in the first stages of pyrolysis a highly porous structure is formed ${ }^{90-92}$ but further heating produces a collapse of the porosity due to the viscous flow process within the amorphous structure ${ }^{93}$. Such behaviour is consistent with the proposed diffusion mechanisms. 

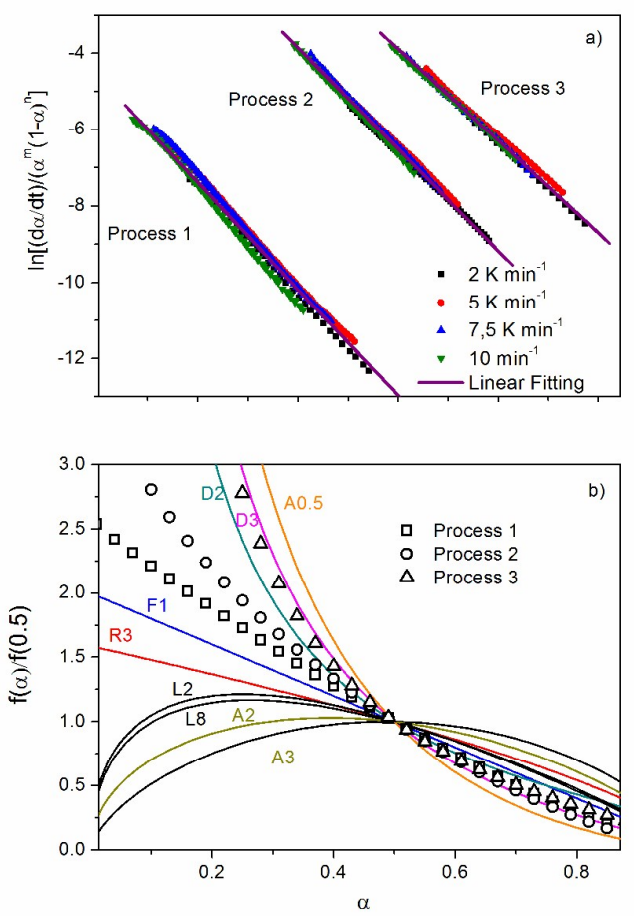

Figure 7. a) Combined kinetic plots, (as per Eq (5)) obtained by deconvolution of the overall TTCS degradation curves. b) Comparison of the $\mathrm{f}(\alpha)$ functions normalized at $\alpha=0.5$ corresponding to some of the ideal kinetic models included in Table 1 (solid lines) with the kinetic models (symbols) obtained for each of the three contributing process determined for the thermal degradation of TTCS. $(\square)$ first process, $(\circ)$ second process and $(\triangle)$ third process

Nevertheless, in order to validate the proposed set of kinetic parameters, simulated kinetic curves were constructed assuming the aforementioned kinetic parameters and the same heating schedules used to obtain the experimental curves. The simulations were performed by means of a $4^{\text {th }}$ order numerical integration Runge-Kutta method; using Eq. (1) and the equations that define the linear heating rate conditions, i.e. $\beta=d T / d t$. As Figure 4 shows, both the reconstructed (simulated) curves and the experimental ones match closely, proving the validity of the kinetic parameters obtained from the combined analysis. It is important to emphasize that the successful modelling of a global process of such complexity and the reconstruction of the experimental curves is very difficult to achieve and it is therefore seldom found in literature. Even more remarkable is the ability of the calculated kinetic parameters to predict the behaviour of 
the material under heating schedules different of those employed to perform the kinetic analysis, as it will be shown later on.

\section{Kinetic study of the thermal degradation of Polyureamethylvinilsilazane (CERASET)}

Figure 1 shows the experimental mass-T curve corresponding to the degradation of CERASET precursor under linear heating rate conditions $\left(5 \mathrm{~K} \mathrm{~min}^{-1}\right)$ whereas Figure 8 shows a set of $\alpha$-T curves, constructed as per Eq (2), recorded under linear heating rate conditions (1, 2, 5 and 10 $\mathrm{K} \mathrm{min}^{-1}$ ). Curves exhibit a complex shape that suggests the overall process is again not simple but it is composed of at least two contributing reactions. The total mass loss, about $15 \%$ of the initial mass, and the shape profiles of all curves are similar regardless of the heating rate as it happens in the case of the TTCS precursor, indicating that the involved reactions are also probably independent rate limiting processes.

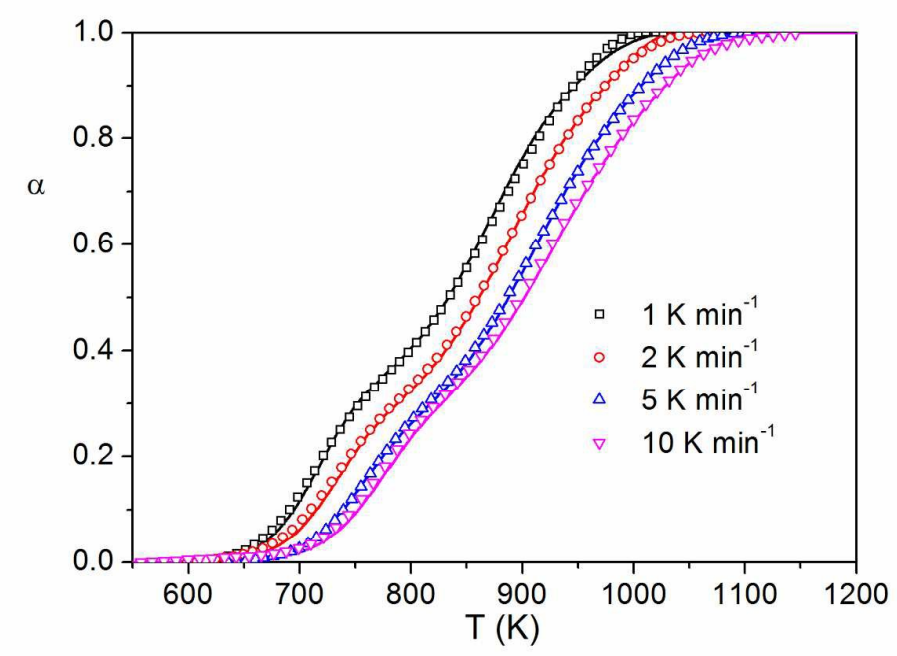

Figure 8. Experimental $\alpha$-T curves (symbols) recorded for the thermal decomposition of the Ceraset precursor in Ar gas flow using linear heating rates of 1, 2, 5 and $10 \mathrm{~K}$ min-1. Reconstructed curves (solid lines) were built employing the kinetic parameters provided by the combined analysis method and listed in Table 4. 
The approach used to study the decomposition kinetics of the Ceraset precursor is the same used in the previous section. Table 2 lists the apparent activation energy of the overall process as a function of the conversion as calculated by means of the Friedman isoconversional analysis, using all experimental curves included in Figure 8 simultaneously. A variable apparent activation energy is obtained, ranging from 150 to $220 \mathrm{~kJ} \mathrm{~mol}^{-1}$. Such variation is expected in a complex reaction composed of several overlapping processes, when the overall apparent activation energy would depend on the activation energies of the different contributing processes and their relative weight at each reacted fraction.

Figure 9 includes the $\mathrm{d} \alpha / \mathrm{dt}-\mathrm{T}$ curve corresponding to the experiment recorded at $5 \mathrm{~K}$ $\min ^{-1}$, obtained by derivation of the integral $\alpha$-T curve, together with the MS intensity-T profiles of several selected $\mathrm{m} / \mathrm{z}$ monitored by MS. In this case, the number of involved processes is not as readily apparent for only two broad peaks are evident at a first glance in the differential TG curve. Nevertheless, a careful study of the MS curves reveals four different types of intensity-T profiles. The $\mathrm{m} / \mathrm{z}$ profiles not shown in the figures can be found in the Supplementary Information (Figures S8 and S10).

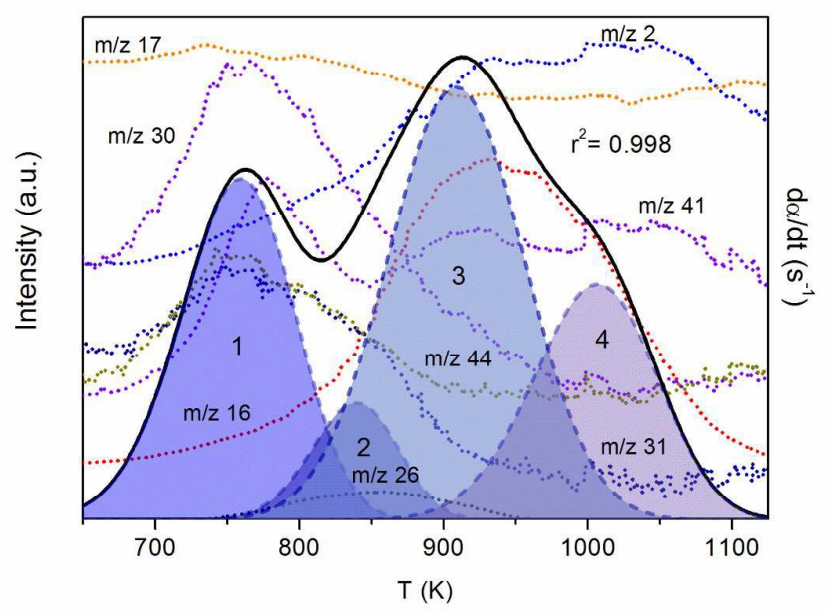

Figure 9. Experimental d $\alpha / \mathrm{dt}-\mathrm{T}$ (solid line) and intensity-T profiles (dotted lines) for several significant $\mathrm{m} / \mathrm{z}$ values obtained for the thermal decomposition of Ceraset precursor at a linear heating rate $5 \mathrm{~K} \mathrm{~min}^{-1}$ and the Fraser-Suzuki function (dotted lines with coloured areas) used for fitting the simulated curves. The correlation coefficient of the fitting has been included into the figure. 
In a first broad process $(650 \mathrm{~K}<\mathrm{T}<875 \mathrm{~K})$ some traces of $\mathrm{NH}_{3}(\mathrm{~m} / \mathrm{z}=17)$ are observed, a result of transamination reactions involving the formation of new $\mathrm{Si}-\mathrm{N}$ bonds and the release of $\mathrm{NH}_{3}{ }^{94-97}$. In this process it is also detected an evolution of hydrogen $(\mathrm{m} / \mathrm{z}=2)$ due to dehydrogenation reactions ${ }^{94-99}$, small quantities of methane $(\mathrm{m} / \mathrm{z}=16,15,14)$ and silane species $\left(\mathrm{SiH}_{2}{ }^{2+}, \mathrm{SiH}_{3}{ }^{+}\right.$and $\mathrm{SiH}_{4}(\mathrm{~m} / \mathrm{z}: 44,31,30)$ due to redistribution reactions ${ }^{94-}$ ${ }^{97}$ that involves exchange of $\mathrm{Si}-\mathrm{N}$ and $\mathrm{Si}-\mathrm{H}$ bonds accompanied by a release of volatile silane species (transamination reactions) ${ }^{95}$. The second process, which occurs between $750 \mathrm{~K}$ and $920 \mathrm{~K}$, is associated to the evolution of hydrogen, methane and ethane $(\mathrm{m} / \mathrm{z}$ : $28,27,26)$. The emission of gaseous hydrocarbon $\left(\mathrm{CH}_{4}, \mathrm{C}_{2} \mathrm{H}_{6}\right.$, etc. $)$ and hydrogen can be explained by the breakage of Si-C and N-C bonds and also Si-H, C-H and N-H bonds (dehydrocoupling reactions) ${ }^{94,95,97}$. The third and four processes heavily overlaps and are difficult to discriminate. Process 3, detected in the range from $825 \mathrm{~K}$ to $950 \mathrm{~K}$, is characterized by the release of a large amount of $\mathrm{CH}_{4}$ and traces of ethane and propene formed as a result of dehydrocoupling reactions. They appear as shoulders in the corresponding $\mathrm{m} / \mathrm{z}$ intensity profiles. Lastly, the fourth process manifests at 950-1100 K as an increase in the signals corresponding to hydrogen and propene ${ }^{94-97}$. Thus, it can be assumed that this highly complex system is composed of four contributing stages, one per each of the distinct peaks appearing in the MS intensity-T plot. As a sidenote, it should be pointed out that the nature of the inert gas has a strong influence on the reactions that take place during the thermal decomposition. For example, Ceraset ceramified in argon atmosphere yields a mixture of crystalline $\beta$-SiC and free carbon whereas a mixture of carbon and nanocrystalline $\beta-\mathrm{SiC}, \alpha-\mathrm{Si}_{3} \mathrm{~N}_{4}$ and $\beta-\mathrm{Si}_{3} \mathrm{~N}_{4}$ is obtained when the ceramification is carried out in nitrogen. Therefore, changing the atmosphere from Argon to Nitrogen would entail a significant change in the polymerto-ceramic process, and would need to be separately studied. This study in principle only applies to the ceramification process when carried out in nitrogen.

In the same way as done in the study of the TTCS precursor decomposition, the overall curve was fitted using four Frasier-Suzuki functions, each centered at the temperature at which the MS intensity profiles exhibit a maximum. Figure 9 shows as an example the results of applying the deconvolution method to the curve recorded at $5 \mathrm{~K} \mathrm{~min}^{-1}$. The deconvolution of curves recorded at different heating rates can be found in Supplementary Information (Figures S7a, S7b. and S7c.). It is clear how the da/dt-T 
overall curves can be very accurately fitted with four Fraser-Suzuki functions (Supplementary Information, Table S2). The relative contribution of each step to the overall reaction, as calculated by integrating the area under the curve, remains constant whatever the heating rate employed. The contributions of the first, second, third and fourth processes to the overall curve are $28 \pm 1 \%, 8 \pm 1 \%, 43 \pm 1 \%$ and $21 \pm 1 \%$ respectively, what proves the independency of constituent reactions. The deconvolved curves were then integrated into $\alpha$-T curves and subsequently differentiated in order to analyze them individually by means of the isoconversional and combined kinetic analysis as described in the theoretical section. The apparent activation energy as a function of the conversion, as calculated using the Friedman isoconversional method, was found to be approximately constant along the entire conversion range for every process (Figure 10), resulting in average activation energies of 154, 173, 255 and $218 \mathrm{~kJ}$ $\mathrm{mol}^{-1}$ for the four respective processes. It is worth noting that the apparent activation energies of the individual processes are in agreement with the variable activation energy obtained for the overall process (Table 2). Thus, the overall apparent activation energy of about $150 \mathrm{~kJ} \mathrm{~mol}^{-1}$ found for low conversion values matches that of the first process, which is occurring in isolation. Once the second, third and fourth processes begin, which happen at about the same time, a value of about $200-220 \mathrm{~kJ} \mathrm{~mol}^{-1}$ is obtained, which is an average of the activation energies of the different processes involved.

Figure 11a shows the results of the combined kinetic analysis, with the plot of the lefthand side of $\mathrm{Eq}$ (5) versus the reverse of the temperature resulting from the optimization procedure described in the Section 2. Again, data from all over the conversion range and from every experiment could be almost perfectly fitted to a straight line. The calculated activation energies, preexponential factors, correlation coefficients, $n$ and $m$ values, along with the contribution of each stage are all included in Table 4. 


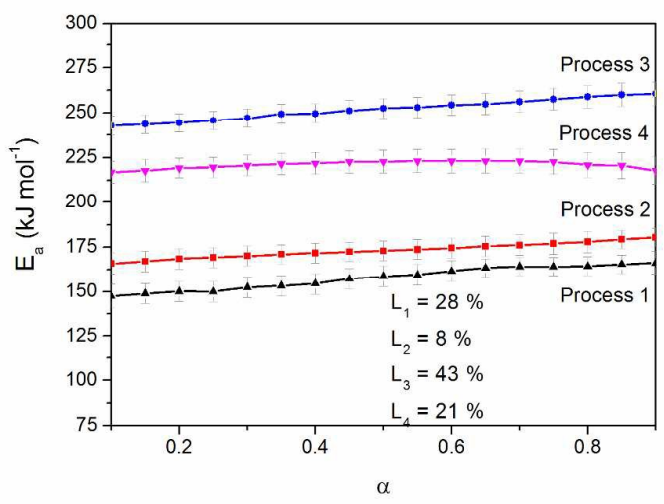

Figure 10. Apparent activation energies at different conversion values for each of the four processes contributing to the thermal decomposition of Ceraset, as determined by the Friedman isoconversional method.
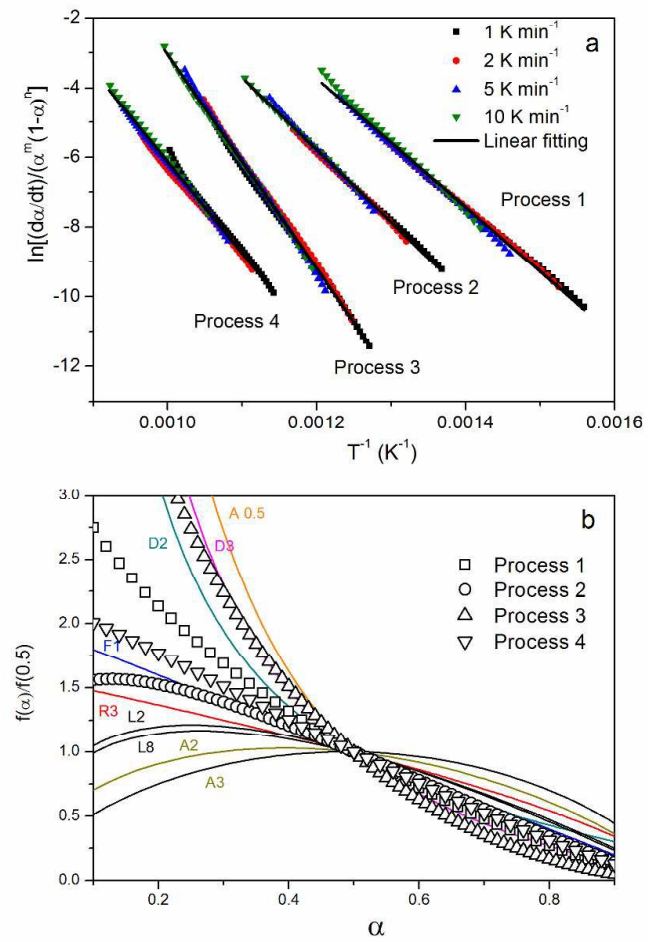

Figure 11. a). Combined kinetic plots, (as per Eq (5)), obtained by deconvolution of the overall Ceraset degradation curves. b) Comparison of the $f(\alpha)$ functions normalized at $\alpha=0.5$ corresponding to some of the ideal kinetic models included in Table 1 (solid lines) with the kinetic models (symbols) obtained for each of the three contributing process determined for the thermal degradation of Ceraset. ( $\square$ ) first process, $(O)$ second process, $(\triangle)$ third process and $(\nabla)$ fourth process. 
Table 4. Apparent activation energies, preexponential factors, correlation coefficients, $n$ and $m$ values for independent stages of global reaction, obtained by the combined kinetic analysis applied after deconvoluting the $\mathrm{d} \alpha / \mathrm{dt}$ curves obtained from the curves showed in Figure 8 (CERASET).

\begin{tabular}{ccccc}
\hline & PROCESS 1 & PROCESS 2 & PROCESS 3 & PROCESS 4 \\
\hline $\boldsymbol{E a}$ (KJ/mol) & $154 \pm 1$ & $172 \pm 1$ & $255 \pm 1$ & $218 \pm 1$ \\
$\boldsymbol{A}\left(\mathbf{s}^{-1}\right)$ & $(1.04 \pm 0.1) \times 10^{8}$ & $(1.95 \pm 0.16) \times 10^{8}$ & $(1.05 \pm 0.09) \times 10^{12}$ & $(5.40 \pm 0.66) \times 10^{8}$ \\
$\boldsymbol{r}$ & 0.998 & 0.999 & 0.999 & 0.997 \\
$\boldsymbol{n}$ & 1.36 & 1.26 & 1.72 & 1.29 \\
$\boldsymbol{m}$ & -0.131 & 0.184 & -0.446 & 0.038 \\
Contribution L (\%) & $28 \pm 1$ & $8 \pm 1$ & $43 \pm 1$ & $21 \pm 1$ \\
\hline
\end{tabular}

The resulting activation energy values are in agreement with the values calculated using Friedman isoconversional analysis. Since the conversion function $f(\alpha)$ estimated by combined kinetic analysis presents no physical meaning by itself, it is necessary to compare it with a set of theoretical kinetic models. Thus, a comparison with some of the most usual theoretical models is included in Figure 11b. Process 1, 3 and 4 appear as diffusion-like mechanisms with some deviations from ideal models in a similar way as it was observed for the TTCS precursor, Process 2 that is the one that has the smallest contribution to the overall reaction, follows a random scission and volatilization type of mode $1^{100}$, this behaviour could be understood considering that during this process the evolved species are light ones, i.e. hydrogen, methane and ethane, and, probably, the random scission of the chain is the limiting kinetic process and not the diffusion. Moreover, this is one of the first processes that take place before the collapse of the porous structure by viscous flow and, therefore, diffusion of light species should be easier. 
The simulated curves, constructed using the kinetic parameters obtained from the combined analysis and the same heating conditions used for recording the experimental curves are plotted in Figure 8, showing that both the reconstructed (simulated) curves and the experimental ones match almost perfectly, proving the validity of the kinetic parameters obtained from the combined analysis.

\section{Prediction of thermal degradation curves under different heating schedules.}

While the successful reconstruction of the experimental curves used to determine the kinetic parameters is normally deemed as sufficient to validate the quality of the analysis, in this work we attempt to prove that the results obtained also have predicting capability for different heating schedules. Thus, Figure 12 includes the curves simulated for TTCS and Ceraset precursors assuming a heating rate of $20 \mathrm{~K} \mathrm{~min}^{-1}$ as well as the corresponding experimental curves that were subsequently recorded. Notice that experimental data points of the $20 \mathrm{~K} \mathrm{~min}^{-1}$ were not employed in any way in the kinetic analysis. Additionally, the heating rate was selected outside the range of 1 to $10 \mathrm{~K} \mathrm{~min}^{-1}$ used in the study since that would make more challenging the prediction success. As Figure 12 shows, the match between the predicted and the real curves are near perfect. Lastly, adding yet another layer of difficulty, a 50\% mixture (w/w) of both TTCS and Ceraset precursors have been prepared and thermally decomposed at $10 \mathrm{~K} \mathrm{~min}^{-1}$. The resulting $\alpha$-T curve is shown in Figure 13, together with the simulated curve assuming such composition and the kinetic parameters previously obtained (Tables 3 y 4 ) for both processes. The predicted curve was built assuming that no reactions occur between both precursors during the decomposition. The excellent reconstruction of experimental curves, even of those not used for the analysis prove that the individual constituent steps obtained from deconvolution out of the overall curves actually correspond to single rate limiting steps and validates that the methodology employed constitute a good approach to model the kinetics of these processes. 


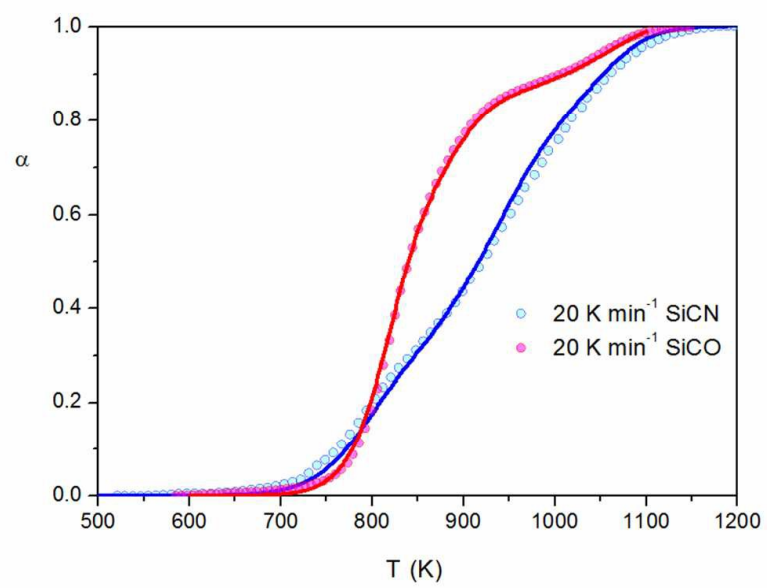

Figure 12. Simulated curves (solid lines) for the thermal decomposition of TTCS and CERASET assuming the kinetic parameters provided by the combined analysis method. Experimental curves (symbols) obtained for the thermal decomposition of CERASET and TTCS at a heating rate of $20 \mathrm{~K} \mathrm{~min}^{-1}$.

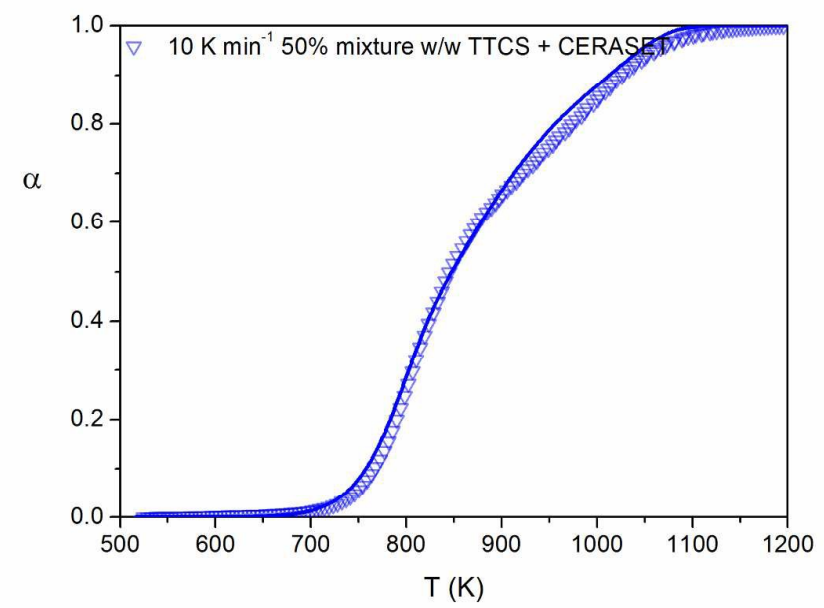

Figure 13. Predicted (simulated) curves (solid lines) obtained for the thermal decomposition of mixed CERASET+TTCS (50\% mixture $\mathrm{w} / \mathrm{w}$ ) assuming the kinetic parameters calculated by the combined analysis method and a heating rate of $10 \mathrm{~K} \mathrm{~min}^{-1}$. Experimental curves (symbols) obtained for the thermal decomposition of CERASET and TTCS (50\% mixture w/w) at linear heating rate $10 \mathrm{~K} \mathrm{~min}^{-1}$ 


\section{Conclusions.}

The kinetic analysis of the thermal decomposition of two commonly employed polymeric precursors, TTCS and CERASET, into their corresponding ceramics has been carried out from coupled TGA-MS experiments. These polymeric precursors undergo complex decomposition processes composed of several largely overlapping steps. Using the different intensity profiles for different $\mathrm{m} / \mathrm{z}$ values as a guide, it was found that TTCS and Ceraset decompose in argon through three and four independent steps respectively. In order to study such a complex process, the overall $\mathrm{d} \alpha / \mathrm{dt}-\mathrm{T}$ curves have been resolved into their constituent processes using a semiempirical deconvolution procedure based on the nonsymmetrical Fraser-Suzuki fitting function, which has been proved to be able to reproduce all the theoretical kinetic models described in literature. Subsequently, the already separated contributing processes have been independently studied using a combined isoconversional-combined analysis approach in order to determine their corresponding kinetic parameters. It has been found the different contributing processes mostly obey diffusion-like kinetic models due to the gaseous diffusion of the released gases through the solid polymer matrix being the limiting step. Finally, the kinetic triplets thus obtained were rigorously validated not only by reconstructing the original experimental curves but also by successfully predicting curves recorded at heating rates outside the range used for obtaining the kinetic parameters. Furthermore, the degradation curve of a mixture of both precursors was also successfully predicted. While the decomposition kinetics might vary for different preceramic precursors or when using different reactive or inert atmospheres, the new kinetic analysis method here presented can be likewise extended to those new situations. More broadly, it proves a promising step forward in the kinetic analysis of complex processes, a topic with growing technical interest and still to be developed.

\section{ACKNOWLEDGMENTS}

Financial support from Projects CTQ2011-27626 and CTQ2014-52763-C2-1-R (MINECO-FEDER), TEP-7858 (Junta Andalucía-FEDER), and TEP-1900 (Junta Andalucía-FEDER) is acknowledged. Additionally, C.G.G is supported by a F.P.I grant from the Spanish MINECO and P.S.J. is supported by a Marie Curie-Junta de Andalucía Talentia grant. The authors also thank VPPI-US for the AP current contract. 


\section{SUPPORTING INFORMATION}

The Supporting Information includes several figures of experimental curves of ceramification processes of TTCS and CERASET and simulated curves at different heating rates. Also the Supporting Information includes the fitting parameters obtained by Fraser-Suzuki deconvolution for the ceramification of TTCS and CERASET. The results obtained by TGA coupled mass spectrometer during the ceramification of TTCS and CERASET at different heating rates have been included in this document.

\section{References}

1. P. Colombo, E. Bernardo and G. Parcianello, Journal of the European Ceramic Society, 2013, 33, 453-469.

2. P. Miele, S. Bernard, D. Cornu and B. Toury, Soft Materials, 2006, 4, 249-286.

3. R. Riedel, G. Mera, R. Hauser and A. Klonczynski, Journal of the Ceramic Society of Japan, 2006, 114, 425-444.

4. B. V. Manoj Kumar and Y.-W. Kim, Science and Technology of Advanced Materials, 2010, 11, 044303.

5. F. h. W. Joachim Bill, Fritz Aldinger, Precursor-Derived Ceramics: Synthesis, Structures and High temperature Mechanical Properties., 1999.

6. D. Su, Y.-L. Li, H.-J. An, X. Liu, F. Hou, J.-Y. Li and X. Fu, Journal of the European Ceramic Society, 2010, 30, 1503-1511.

7. R. R. Wills, R. A. Markle and S. P. Mukherjee, American Ceramic Society Bulletin, 1983, 62, 904-\&.

8. P. Colombo, G. Mera, R. Riedel and G. D. Sorarù, Journal of the American Ceramic Society, 2010, 93, 1805-1837.

9. E. Bernardo, L. Fiocco, G. Parcianello, E. Storti and P. Colombo, Materials, 2014, 7, 1927-1956.

10. Y. Arai, Chemistry of Power Production, Chapman \& Hall, Glasgow, 1996.

11. R. M. Laine and F. Babonneau, Chemistry of Materials, 1993, 5, 260-279.

12. Y.-L. L. Edwin Kroke, Christoph Konetschny, Emmanuel Lecomte, Claudia Fasel, Ralf Riedel, Materials Science and Engineering, 2000, 26, 97-199.

13. P. Greil, Advanced Engineering Materials, 2000, 2, 339-348.

14. G. P., Journal of the European Ceramic Society, 1998, 18, 1905-1914.

15. S. M. Riedel R., Mayer J. and Szabó V., Journal of the European Ceramic Society, 1995, 15, 703-715.

16. T. Konegger, A. Liersch, C. Gierl and M. Scheffler, Advanced Engineering Materials, 2013, 15, 394-406.

17. M. M. Colombo P., Journal of the American Ceramic Society, 1999, 82, 573-578.

18. L. Gottardo, S. Bernard, C. Gervais, K. Inzenhofer, G. Motz, M. Weinmann, C. Balan and P. Miele, Journal of Materials Chemistry, 2012, 22, 7739-7750.

19. M. Zaheer, T. Schmalz, G. Motz and R. Kempe, Chemical Society reviews, 2012, 41, 5102-5116. 
20. R. M. Rocha, J. C. Bressiani and A. H. A. Bressiani, Ceramics International, 2014, 40, 13929-13936.

21. S. Bernard, D. Cornu, P. Miele, M. Weinmann and F. Aldinger, in Mechanical Properties and Performance of Engineering Ceramics and Composites, ed. E. LaraCurzio, 2005, vol. 26, pp. 35-42.

22. E. Erdem, V. Mass, A. Gembus, A. Schulz, V. Liebau-Kunzmann, C. Fasel, R. Riedel and R.-A. Eichel, Physical Chemistry Chemical Physics, 2009, 11, 5628.

23. K. Wang, B. Ma, X. Li, Y. Wang, L. An and R. Riedel, Journal of the American Ceramic Society, 2014, 97, 2135-2138.

24. L. Duan and Q. Ma, Ceramics International, 2012, 38, 2667-2671.

25. G. D. Sorarù, R. Pena-Alonso and H.-J. Kleebe, Journal of the European Ceramic Society, 2012, 32, 1751-1757.

26. A. H. Tavakoli, P. Gerstel, J. A. Golczewski and J. Bill, Acta Materialia, 2010, 58, 60026011.

27. J. Kaspar, M. Graczyk-Zajac and R. Riedel, Journal of Power Sources, 2013, 244, 450455.

28. Y. Wang, J. Ding, W. Feng and L. An, Journal of the American Ceramic Society, 2011, 94, 359-362.

29. C. P. H. J. R. S. D.L., Journal of the American Ceramic Society, 2002, 85, 2306-2312.

30. Y. Wang, H. Li, L. Zhang and L. Cheng, Ceramics International, 2009, 35, 1129-1132.

31. Q. Li, X. Yin and L. Feng, Ceramics International, 2012, 38, 6015-6020.

32. V. L. Nguyen, C. Zanella, P. Bettotti, G. D. Sorarù and R. Hay, Journal of the American Ceramic Society, 2014, 97, 2525-2530.

33. R. A. S. Li-Anne Liew, Victor M. Bright, and J. W. D. Martin L. Dunn, Rishi Raj, Sensors and Actuators A, 2003, 103, 171-181.

34. M. Schulz, Adv. Appl. Ceram., 2009, 108, 454-460.

35. K. Terauds, P. E. Sanchez-Jimenez, R. Raj, C. Vakifahmetoglu and P. Colombo, Journal of the European Ceramic Society, 2010, 30, 2203-2207.

36. D. Seo, S. Jung, S. J. Lombardo, Z. C. Feng, J. K. Chen and Y. Zhang, Sensors and Actuators A: Physical, 2011, 165, 250-255.

37. N. R. Nagaiah, J. S. Kapat, L. An and L. Chow, Journal of Physics: Conference Series, 2006, 34, 458-463.

38. J. Shen and R. Raj, Journal of Power Sources, 2011, 196, 5945-5950.

39. M. Wilamowska, V. S. Pradeep, M. Graczyk-Zajac, R. Riedel and G. D. Sorarù, Solid State lonics, 2014, 260, 94-100.

40. D. Ahn and R. Raj, Journal of Power Sources, 2011, 196, 2179-2186.

41. M. Graczyk-Zajac, L. Toma, C. Fasel and R. Riedel, Solid State lonics, 2012, 225, 522526.

42. P. E. Sanchez-Jimenez and R. Raj, Journal of the American Ceramic Society, 2010, 93, 1127-1135.

43. P. Dibandjo, M. Graczyk-Zajac, R. Riedel, V. S. Pradeep and G. D. Soraru, Journal of the European Ceramic Society, 2012, 32, 2495-2503.

44. M. Graczyk-Zajac, C. Fasel and R. Riedel, Journal of Power Sources, 2011, 196, 64126418.

45. R. Kolb, C. Fasel, V. Liebau-Kunzmann and R. Riedel, Journal of the European Ceramic Society, 2006, 26, 3903-3908.

46. R. Riedel, A. Kienzle, W. Dressler, L. Ruwisch, J. Bill and F. Aldinger, Nature, 1996, 382, 796-798.

47. G. M. Ralf RIEDEL, Ralf HAUSER and Alexander KLONCZYNSKI, Journal of the Ceramic Society of Japan, 2006, 114, 425-444.

48. S. F. Bernard, K.; Cornu, D.; Miele, P.; Laurent, P.;, Journal of Physical Chemistry B, 2006, 110, 9048-9060. 
49. G. D. P. Soraru, L.; Latournerie, J.; Rishi, R., Journal of the American Ceramic Society, 2002, 85, 2181-2187.

50. X. Wang, J. Wu, Y. Li, C. Zhou and C. Xu, Journal of Thermal Analysis and Calorimetry, 2013, 115, 55-62.

51. M. J. Almond, R. Becerra, S. J. Bowes, J. P. Cannady, J. S. Ogden and R. Walsh, Physical chemistry chemical physics : PCCP, 2008, 10, 6856-6861.

52. M. J. Almond, R. Becerra, S. J. Bowes, J. P. Cannady, J. S. Ogden, N. A. Young and R. Walsh, Physical chemistry chemical physics : PCCP, 2009, 11, 9259-9267.

53. G. D. Soraru and L. Pederiva, Journal of the American Ceramic Society, 2002, 85, 21812187.

54. P. E. Sánchez-Jiménez, M. d. R. Rodríguez-Laguna, L. A. Pérez-Maqueda and J. M. Criado, Applied Energy, 2014, 125, 132-135.

55. A. Perejon, P. E. Sanchez-Jimenez, J. M. Criado and L. A. Perez-Maqueda, The journal of physical chemistry. B, 2011, 115, 1780-1791.

56. N. Koga, Y. Goshi, S. Yamada and L. A. Pérez-Maqueda, Journal of Thermal Analysis and Calorimetry, 2012, 111, 1463-1474.

57. M. T. Taghizadeh, N. Yeganeh and M. Rezaei, Journal of Thermal Analysis and Calorimetry, 2014, 118, 1733-1746.

58. M. Erceg, D. Jozić, I. Banovac, S. Perinović and S. Bernstorff, Thermochimica Acta, 2014, 579, 86-92.

59. S. Z. Qi-Long Yan, Jian-Guo Zang,Piao He, Tomás Musil and Monika Bartoskova, Phys.Chem.Chem.Phys., 2014, 16, 24282-24291.

60. R. Svoboda and J. Málek, Journal of Thermal Analysis and Calorimetry, 2012, 111, 1045-1056.

61. R. Svoboda and J. Málek, Journal of Thermal Analysis and Calorimetry, 2013, 115, 8191.

62. A. Perejón, P. E. Sánchez-Jiménez, J. M. Criado and L. A. Pérez-Maqueda, The Journal of Physical Chemistry C, 2014, 118, 26387-26395.

63. Z. Cheng, W. Wu, P. Ji, X. Zhou, R. Liu and J. Cai, Journal of Thermal Analysis and Calorimetry, 2014, 119, 1429-1438.

64. X. Yang, X. Wang, B. Zhao and Y. Li, BioEnergy Research, 2014, 7, 1293-1304.

65. T. Wada and N. Koga, The journal of physical chemistry. A, 2013, 117, 1880-1889.

66. M. Yoshikawa, S. Yamada and N. Koga, The Journal of Physical Chemistry C, 2014, 118, 8059-8070.

67. J. M. Criado, P. E. Sanchez-Jimenez and L. A. Perez-Maqueda, Journal of Thermal Analysis and Calorimetry, 2008, 92, 199-203.

68. H. L. Friedman, Journal of Polymer Science Part C-Polymer Symposium, 1964, 183-\&.

69. S. Vyazovkin and N. Sbirrazzuoli, Macromolecular Rapid Communications, 1999, 20, 387-389.

70. S. Vyazovkin and C. A. Wight, Thermochimica Acta, 1999, 341, 53-68.

71. L. A. Perez-Maqueda, J. M. Criado and J. Malek, J. Non-Cryst. Solids, 2003, 320, 84-91.

72. L. A. Perez-Maqueda, J. M. Criado and P. E. Sanchez-Jimenez, Journal of Physical Chemistry A, 2006, 110, 12456-12462.

73. C. Pantano, A. Singh and H. Zhang, J Sol-Gel Sci Technol, 1999, 14, 7-25.

74. A. C. Ferrari and J. Robertson, Physical Review B - Condensed Matter and Materials Physics, 2000, 61, 14095-14107.

75. A. C. Ferrari, J. C. Meyer, V. Scardaci, C. Casiraghi, M. Lazzeri, F. Mauri, S. Piscanec, D. Jiang, K. S. Novoselov, S. Roth and A. K. Geim, Physical Review Letters, 2006, 97.

76. A. C. Ferrari, Solid State Communications, 2007, 143, 47-57.

77. L. G. Cançado, K. Takai, T. Enoki, M. Endo, Y. A. Kim, H. Mizusaki, A. Jorio, L. N. Coelho, R. Magalhães-Paniago and M. A. Pimenta, Applied Physics Letters, 2006, 88, 163106. 
78. M. A. Pimenta, G. Dresselhaus, M. S. Dresselhaus, L. G. Cançado, A. Jorio and R. Saito, Physical Chemistry Chemical Physics, 2007, 9, 1276-1291.

79. C. Turquat, H. J. Kleebe, G. Gregori, S. Walter and G. D. Sorarù, Journal of the American Ceramic Society, 2001, 84, 2189-2196.

80. A. Lee Smith, Spectrochim Acta, 1960, 16, 87-105.

81. D. Bahloul-Hourlier, J. Latournerie and P. Dempsey, Journal of the European Ceramic Society, 2005, 25, 979-985.

82. G. D. Soraru, G. D'Andrea, R. Campostrini, F. Babonneau and G. Mariotto, Journal of the American Ceramic Society, 1995, 78, 379-387.

83. Q. Liu, W. Shi, F. Babonneau and V. Interrante, Chem. Mater., 1997, 9, 2434-2441.

84. V. GUALANDRIS, D. Hourlier-Bahloul and F. Babonneau, J. Sol-gel Sci. Technol., 1998, 14, 39-48.

85. R. Campostrini, G. G'Andrea, G. Carturan, R. Ceccato and G. D. Soraru, Journal of Materials Chemistry, 1996, 6, 585-594.

86. V. C. Belot, R.J.P.; Leclerq, D.; Mutin, P.H.; Vioux, A., Journal of Non-Crystalline Solids, 1992, 147-148, 52-55.

87. V. C. Belot, R.J.P.; Leclerq, D.; Mutin, P.H.; Vioux, A., Journal of Polymer Science Part APolymer Chemistry, 1992, 30, 613-623.

88. P. H. Mutin, Journal of the American Ceramic Society, 2002, 85, 1185-1189.

89. R. R. Colombo P., Sorarú G. D., Kleebe H. J., Polymer derived ceramics from nanostructure to applications, DEStech Publications, Inc., Lancaster, Pennsylvania 17602 U.S.A., 2010.

90. M. Wilhelm, C. Soltmann, D. Koch and G. Grathwohl, Journal of the European Ceramic Society, 2005, 25, 271-276.

91. H. Schmidt, D. Koch, G. Grathwohl and P. Colombo, Journal of the American Ceramic Society. American Ceramic Society, 2001, 84, 2252-2255.

92. T. Konegger, L. F. Williams and R. K. Bordia, Journal of the American Ceramic Society. American Ceramic Society, 2015, 98, 3047-3053.

93. P. E. Sánchez-Jiménez, J. A. Downs and R. Raj, Journal of the American Ceramic Society, 2010, 93, 2567-2570.

94. Y.-L. Li, E. Kroke, R. Riedel, C. Fasel, C. Gervais and F. Babonneau, Applied Organometallic Chemistry, 2001, 15, 820-832.

95. D. Bahloul-Hourlier, M. Pereira and C. Gérardin, J. Mater. Chem., 1997, 7, 109-116.

96. C. Gérardin, F. Taulelle and D. Bahloul-Hourlier, J. Mater. Chem., 1997, 7, 117-126.

97. D. Bahloul, M. Pereira, P. Goursat, N. S. Choong, K. Yive and R. J. P. Corriu, Journal of the American Ceramic Society, 1993, 76, 1156-1162.

98. M. Peuckert, T. Vaahs and M. Brück, Advanced Materials, 1990, 2, 398-404.

99. Y. D. Blum, K. B. Schwartz and R. M. Laine, Journal of Materials Science, 1989, 24, 1707-1718.

100. P. E. Sánchez-Jiménez, L. A. Pérez-Maqueda, A. Perejón and J. M. Criado, Polymer Degradation and Stability, 2010, 95, 733-739. 


\section{Figure Captions}

Figure 1. Experimental mass\%-T curves recorded for the thermal decomposition of CERASET and TTCS in Ar gas flow and using a linear heating rate of $5 \mathrm{~K} \mathrm{~min}^{-1}$.

Figure 2. Raman spectra of the powders collected after interrupting the pyrolysis of (a) TTCS precursor and (b) CERASET precursor at $823 \mathrm{~K}, 1023 \mathrm{~K}, 1273 \mathrm{~K}$.

Figure 3. a) FTIR spectra obtained for the initial cross-linked precursor and the powders collected after interrupting the pyrolysis at $823,1023,1273 \mathrm{~K}$ of TTCS precursor. b) FTIR spectra obtained for the initial cross-linked precursor and the powders collected after interrupting the pyrolysis at $823,1023,1273 \mathrm{~K}$ of CERASET precursor.

Figure 4. Experimental $\alpha$-T curves (symbols) recorded for the thermal decomposition of TTCS in Ar flow using linear heating rates of 2, 5, 7.5 and $10 \mathrm{~K} \mathrm{~min}^{-1}$. Simulated curves (solid lines) were constructed using the kinetic parameters calculated for TTCS thermal decomposition by the combined analysis method and listed in Table 3.

Figure 5. Experimental d $\alpha / \mathrm{dt}-\mathrm{T}$ (solid line) and intensity-T profiles (dotted lines) for several $\mathrm{m} / \mathrm{z}$ ratios obtained for the thermal decomposition of TTCS recorded at $5 \mathrm{~K} / \mathrm{min}$, along with the Fraser-Suzuki function (dotted lines with coloured areas) used for fitting the simulated curves. The correlation coefficient of the fitting has been included into the figure.

Figure 6. Apparent activation energies at different conversion values for each of the three processes contributing to the thermal decomposition of TTCS, as determined by the Friedman isoconversional method

Figure 7. a) Combined kinetic plots, (as per Eq (5)), of each set of $\alpha$-T curves obtained by deconvolution of the overall TTCS degradation curves. The results of the optimization procedure for three independent stages. b) Comparison of the $f(\alpha)$ functions normalized at $\alpha=$ 0.5 corresponding to some of the ideal kinetic models included in Table 1 (solid lines) with the kinetic models (symbols) obtained for each of the three contributing process determined for the thermal degradation of TTCS. ( $\square$ ) first process, ( $)$ second process and ( $\square$ ) third process

Figure 8. Experimental $\alpha$-T curves (symbols) recorded for the thermal decomposition of the Ceraset precursor in Ar gas flow using linear heating rates of 1, 2, 5 and $10 \mathrm{~K}$ min-1. Reconstructed curves (solid lines) were built employing the kinetic parameters provided by the combined analysis method and listed in Table 4.

Figure 9. Experimental d $\alpha / \mathrm{dt}-\mathrm{T}$ (solid line) and intensity-T profiles (dotted lines) for several significant $\mathrm{m} / \mathrm{z}$ values obtained for the thermal decomposition of Ceraset precursor at a linear heating rate $5 \mathrm{~K} \mathrm{~min}^{-1}$ and the Fraser-Suzuki function (dotted lines with coloured areas) used for fitting the simulated curves. The correlation coefficient of the fitting has been included into the figure. 
Figure 10. Apparent activation energies at different conversion fraction for each of the four processes contributing to the thermal decomposition of Ceraset, as determined by Friedman isoconversional method.

Figure 11.a) Combined kinetic plots, (as per Eq (5)), of each set of $\alpha$-T curves obtained by deconvolution of the overall Ceraset degradation curves. b) Comparison of the $f(\alpha)$ functions normalized at $\alpha=0.5$ corresponding to some of the ideal kinetic models included in Table 1 (solid lines) with the kinetic models (symbols) obtained for each of the three contributing process determined for the thermal degradation of Ceraset. ( $\square$ ) first process, ( $($ ) second process, ( $\square$ ) third process and ( $\square$ ) fourth process.

Figure 12. Predicted curves (solid lines) for the thermal decomposition of TTCS and CERASET assuming the kinetic parameters provided by the combined analysis method. Experimental curves (symbols) obtained for the thermal decomposition of CERASET and TTCS at a heating rate of $20 \mathrm{~K} \mathrm{~min}^{-1}$.

Figure 13. Predicted (simulated) curves (solid lines) obtained for the thermal decomposition of mixed CERASET+TTCS (50\% mixture w/w) assuming the kinetic parameters calculated by the combined analysis method and a heating rate of $10 \mathrm{~K} \mathrm{~min}^{-1}$. Experimental curves (symbols) obtained for the thermal decomposition of CERASET and TTCS ( $50 \%$ mixture w/w) at linear heating rate $10 \mathrm{~K} \mathrm{~min}^{-1}$. 